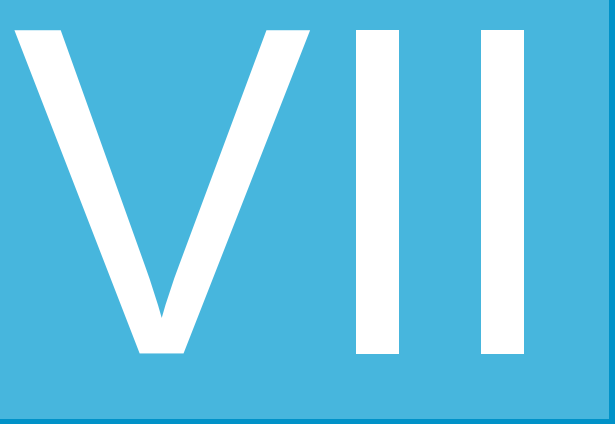

\title{
MAESTROS, IDEAS Y LECTURAS QUE CAMBIARON EL PENSAMIENTO DE CHARLES ROBERT DARWIN
}

Teachers, ideas, and readings that shaped the thought of Charles Robert Darwin

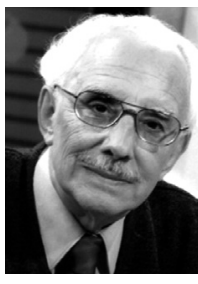

\section{Juan Carlos Priora}

Graduado en Historia por la Universidad Nacional del Sur (Argentina). Estudios de posgrado en las universidades nacionales de La Plata y Córdoba (Argentina), y en Complementación Teológica por el Seminario Adventista Latinoamericano de Teología. Fue decano de la Facultad de Humanidades, Educación y Ciencias Sociales de la Universidad Adventista del Plata; desde el año 2007 profesor emérito vitalicio de dicha universidad. Autor de siete libros, decenas de artículos científicos y unos 150, de divulgación. Además de Argentina, ha dictado clases, seminarios, cursos y conferencias en Colombia, Brasil, Ecuador, España, EE. UU., México, Venezuela y Uruguay. 


\section{Resumen}

En este ensayo nos proponemos exponer quiénes fueron los maestros, qué lecturas, ideas y qué otras circunstancias impactaron, definidamente, sobre la estructura mental de Darwin, al punto de hacerle abandonar algunas ideas y adoptar otras. Al hablar de Charles Darwin, nos ocuparemos de sus ancestros, sus estudios, sus maestros, sus amistades, sus lecturas y las dudas que lo acuciaron durante su existencia. En síntesis, de todo ese bagaje de experiencias que formó y transformó su pensamiento, al punto de producir una obra que revolucionó al mundo.

Palabras clave: Fijismo, uniformismo, catastrofismo, variación, selección natural, especiación, supervivencia del más apto, evolución.

\section{Abstract}

This paper sets out to review Charles Darwin's teachers, readings, and which ideas and other events had a definite impact on his mental framework, to the extent that they prompted him to dismiss some ideas while adopting others. When discussing Charles Darwin, we will devote to his ancestors, studies, teachers, friendships, readings, and the doubts that nagged him throughout his life. In short, we will refer to the whole collection of the personal experiences that shaped and transformed his thought, to the point of prompting him to write a book that shook up the world.

Keywords: Fixism, uniformism, catastrophism, variations, natural selection, speciation, survival of the fittest, evolution. 


\section{Introducción}

La historia es pródiga en ejemplos que muestran la influencia que han ejercido hombres o libros, sobre otros hombres. Nadie es totalmente original en sus ideas, todos le debemos algo a alguien, pero hubo maestros o libros, en función de tales, que cambiaron la manera de pensar de otros. Este es el caso de Charles Robert Darwin (1809-1882). Su pensamiento original fue alterado por lecturas, pero, fundamentalmente, por las enseñanzas de algunos de sus maestros.

En este ensayo nos proponemos exponer quiénes fueron esos maestros, qué lecturas y qué otras circunstancias impactaron, definidamente, sobre la estructura mental de Darwin, al punto de hacerle abandonar algunas ideas y adoptar otras.

No por archiconocida, ha dejado de tener vigencia la afirmación del filósofo español José Ortega y Gasset (1883-1955) acerca de que "el hombre es él y su circunstancia". Por ese motivo, al hablar de Charles Darwin, nos ocuparemos de sus ancestros, sus estudios, sus maestros, sus amistades, sus lecturas y las dudas que lo acuciaron durante su existencia. En síntesis, de todo ese bagaje de experiencias que formó y transformó su pensamiento, al punto de producir una obra que revolucionó al mundo.

\section{Los ancestros}

Charles Robert Darwin Wedgwood, nació en Shrewsbury, el 12 de febrero de 1809 en el seno de una familia de buena posición económica y de tradición académica. Su padre, Robert Waring Darwin (1766-1848), médico, al igual que su abuelo Erasmus Darwin (1731-1802), quien escribió una obra transformista: Zoonomía o Leyes de la vida Orgánica (1794-1796), que ejerció gran influencia en su nieto.

Cuando falleció su madre Susanah (1765-1817), el padre, que quedó a cargo de seis hijos: (Marianne [1798-1858], Caroline [1800-1888], Susan [18031866], Erasmus Alves[1804-1881], Charles[1809-1882] y Emily [1810-1866]), decidió enviar a los dos varones a una escuela diurna en Shrewsbury.

\section{Los estudios}

En dicha escuela las actividades áulicas les resultaron aburridas. Pero neutralizaba ese malestar dedicándose a coleccionar. Dice en su autobiografía (Darwin, 1996, 23): 
Cuando empecé a asistir a esta escuela diurna, mi gusto por la historia natural y, más específicamente, por coleccionar, estaba ya muy desarrollado. Trataba de descubrir el nombre de las plantas y coleccionaba toda clase de cosas, conchas, timbres, franqueos, monedas y minerales [...].

El padre, visto los magros resultados, y con la intención de brindarle una profesión respetable, lo retiró de esa escuela y lo envió (octubre 1825) a la Universidad de Edimburgo para que estudiara Medicina. Su hermano estaba cursando la misma carrera allí. Desde mediados del S. XVIII esa ciudad era conocida como la "Atenas del norte", con gran actividad intelectual e influencia del iluminismo escocés. La carrera de Medicina era considerada una de las mejores de Europa. Su prestigio se potenció por la asociación con la Universidad Holandesa de Leyden. Las guerras napoleónicas, al impedir que los estudiantes ingleses de Medicina concurrieran a Holanda, convirtieron a Edimburgo en "la Meca" de dichos estudios.

Allí también las clases le parecieron insoportablemente aburridas. Además, le violentaba presenciar las amputaciones sin anestesia.

Erasmus, su hermano, abandonó Edimburgo al año siguiente para continuar su carrera en Londres y, entonces, Charles quedó librado a su propio arbitrio. Abandonó los estudios de Medicina y se dedicó a la Historia Natural. Hizo amistad con estudiantes y docentes que tenían intereses diversos: Un taxidermista de color le enseñó el arte de embalsamar pájaros; otro, llamado Ainsworth viajó por Asiria y se apasionó por la geología; los doctores Coldstream y Robert Grant, ambos zoólogos, lo asociaron a sus investigaciones e incluso lo introdujeron en la Sociedad Pliniana, un club científico en el que se leían ensayos sobre historia natural. Allí expuso una de sus primeras investigaciones. Grant, era un entusiasta de Lamarck. Otro de los conocidos fue el Sr. Leonard Horner, quien lo llevó a una sesión de la Royal Society de Edimburgo presidida por Robert Falcon Scott (1868-1912) el famoso explorador de la Antártica y del Polo Sur. También concurrió a la Royal Medical Society ${ }^{1}$.

El padre, enterado de que su hijo nunca sería médico, decidió mandarlo al Christ.s Collage de Cambridge para que estudie teología con la finalidad de que sea clérigo. Allí estuvo desde 1828 hasta 1831 . He aquí su testimonio (Darwin, 1996, 28,29):

Los tres años que pasé en Cambridge perdí el tiempo, en lo que a los estudios académicos concierne, de manera tan completa como en Edimburgo y

${ }^{1}$ Para conocer mejor la experiencia de Darwin en Edimburgo, v. Burkhardt, F. (Edit.). Cartas de Darwin 1825-1859), 29-33. 
en la escuela. [...] Una vez más en mi último curso trabajé con cierta seriedad para obtener el grado final de Licenciatura en Artes.

[...] Pero no hubo tarea en Cambridge que persiguiera con tanta asiduidad ni que me fuera tan grata como coleccionar escarabajos.

La vocación de Charles Robert era evidente. El único que no la descubrió fue su padre.

En Cambridge conoció a su primo segundo William Darwin Fox, quien lo introdujo en el fascinante campo de la entomología. Además, se granjeó el afecto de dos notables profesores de Cambridge y clérigos anglicanos: John Stevens Henslow (1796-1861), mineralista y botánico, quien lo llevó a las expediciones para recolectar plantas, considerándolo como un hijo; y Adam Sedgwick (1785-1873), geólogo, quien le despertó el gusto por el estudio de la tierra.

\section{Las influencias}

\section{A - Personas y libros}

Las influencias sobre una persona pueden ejercerse desde varios ángulos: Desde otras personas, por las ideologías vigentes de la época y por medio de libros, etc.

Acerca de la importancia de los libros, expresó Robert B. Downs $(1970,11-12)$ :

Un error muy extendido entre el vulgo sostiene que los libros son objetos inanimados, inefectivos, pacíficos, pertenecientes a las sombras claustrales y tranquilidad académica de monasterios, universidades y demás retiros del mundo materialista pervertido.

[...]A lo largo de la historia se acumulan abundantes pruebas de que los libros, en vez de ser fútiles, inofensivos e inocentes, con frecuencia son dinámicos, vitales, capaces de cambiar por completo el curso de los acontecimientos, unas veces para bien y otras para mal.

Los libros del geógrafo, naturalista y viajero infatigable Alexander von Humboldt (1769-1859), despertaron en Darwin un vivo deseo por viajar. ${ }^{2}$

Del astrónomo John Herschel (1792-1871), creador del análisis espectroscópico, descubridor de las radiaciones infrarrojas y autor del libro In-

${ }^{2}$ Algunos de esos libros fueron: Viajes a las regiones equinocciales del Nuevo Continente; Cuadros de la naturaleza; Viajes asiáticos y Cosmos o descripción física del mundo. 
troducción al estudio de la Filosofía Natural, aprendió la importancia de la rigurosidad científica.

\section{B - Ideas y teorías}

Hay ideas que han causado fuertes discusiones y provocado enfrentamientos prolongados. Dos de ellas son el geocentrismo y el heliocentrismo. La primera que sostiene que el Sol y los planetas giran en torno de la Tierra, fue expuesta por el astrónomo y matemático alejandrino (Egipto) Claudio Ptolomeo del S. II a.C., recogidas luego en el Almagesto. Esta idea dominó la astronomía hasta el S. XVI, prohijada por la Iglesia Católica Romana. Hubo excepciones como las afirmaciones de la Biblia, de Aristarco de Samos (S. II a.C.) y del filósofo, matemático, astrónomo y cardenal alemán Nicholas von Kues (conocido como Nicolás Krebs de Cusa, 1401-1464) ${ }^{3}$, que sostenían que la Tierra y los demás planetas del sistema solar giraban en torno del Sol. Esta discusión perduró hasta que el astrónomo polaco Nicolás Copérnico (14731543) respaldó con sus demostraciones la teoría heliocentrista en su notable obra De Revolutionibus Orbium Coelestium (1543)

La formación de la corteza terrestre dio lugar a prolongados enfrentamientos desde el S. VI a.C. hasta nuestros días, entre los que sostenían que la corteza terrestre se formó por acción del agua (neptunistas), del fuego (plutonistas y vulcanistas) y del aire (eolianos). Los catastrofistas-creacionistasdiluvialistas-, se alinearon con los neptunistas enfrentados por los plutonistas. En tiempos de Darwin, hubo un célebre neptunista, el profesor de Freiberg, el alemán Abraham Gottlob Werner (1750-1817) ${ }^{5}$, a quien se le opuso el inglés James Hutton (1726-1797) ${ }^{6}$, partidario del plutonismo y precursor del uniformismo de Charles Lyell (1797-1875). Este geólogo británico fue amigo de Darwin. Escribió una obra fundamental para el evolucionismo: Principios de Geología (1830-1833), en la que afirma que los procesos geológicos se desarrollaron en forma muy lenta y uniforme, por lo cual "el presente es la medida del pasado"; esa es la causa por la que al uniformismo se lo llama

\footnotetext{
${ }^{3}$ Desde hace algunos años un grupo de investigadores de la Universidad Nacional de Buenos Aires se dedica a profundizar en el pensamiento cusano y a publicar sus libros ,v. $\tilde{\mathrm{N}}$, revista de cultura de Clarín, Año IV, N. ${ }^{\circ} 186$ (Buenos Aires, 21 de abril de 2007), 50.

${ }^{4}$ Acerca de lo que significaron las ideas de Copérnico y de su obra, v. Downs, R. (1970). Libros que han cambiado el mundo. Buenos Aires: Aguilar Argentina, cap. 11, 201-218.

${ }^{5} \mathrm{~A}$ Werner se lo considera el fundador de la geología moderna y formulador de la teoría de las "capas de cebolla" o sea que la Tierra está formada por capas concéntricas. V. Dupuy, D. (1948). El desafío de los yacimientos de carbón y petróleo. Montevideo: Impresora L.I.G.U., cap. I. L.I.G.U., 29-31.

${ }^{6}$ Hammërly, D. (1948). El desafio de los yacimientos de carbón y petróleo. Montevideo: Impresora
} 
también actualismo. Un geólogo uniformista dice que mediante la medición de los fenómenos actuales se puede conocer lo que ocurrió, geológicamente, en el pasado; mientras que un catastrofista sostiene que en el pasado e inclusive en el presente, como ocurrió con el surgimiento de la isla Surtsey ${ }^{7}$, se han producido o producen acciones violentas que generan, en poco tiempo, transformaciones geológicas que para los uniformistas requieren millones de años. $^{8}$

Un ejemplar del primer tomo de Lyell lo llevó Darwin cuando se embarcó en el Beagle (1831); el segundo lo recibió el 26 de octubre de 1832 mientras estaba en Sudamérica. Desde que leyó a Lyell, su libro se convirtió en la guía para mirar la naturaleza desde la perspectiva uniformista.

\section{C - El viaje en el Beagle (27.12.1831- 2.10.1836)}

Aunque no se graduó en Teología, a principios de 1831, Darwin rindió el último examen en Cambridge para obtener el título de bachiller en Artes. Después fue instigado por el Prof. Henslow a estudiar geología. De regreso a su pueblo se dedicó a esta disciplina. En eso estaba, cuando el Prof. Sedwick le avisó que realizaría una excursión de estudio por el norte de Gales. Por sugerencia de Henslow, Sedwick invitó a Darwin para que lo acompañara. Incluso se alojó en la casa del exalumno. La utilidad de esta experiencia fue expresada por Charles Robert con estas palabras (Charles Darwin, 1996, 31):

Esta gira tuvo una decisiva utilidad para mí, por cuanto me enseñó un poco cómo comprender la geología de una región.

[...] En esta gira tuve ocasión de ver un asombroso ejemplo de lo fácil que es no advertir fenómenos, por conspicuos que sean, no observados antes por nadie.

Al regresar de su corta expedición por el norte de Gales (agosto), se encontró con una carta del Prof. Henslow, informándole que lo había recomendado al Sr. George Peacock para acompañar al capitán Robert FitzRoy (1805-1865) $)^{9}$ como naturalista en el viaje que realizaría al mando del bergan-

${ }^{7}$ A los científicos les sorprendió el surgimiento de esta isla, nacida abruptamente, después de una erupción volcánica subacuática en el Atlántico norte, al sur de Islandia, en noviembre de 1963. V. Coffin, H. (1969). "El nacimiento de una isla". Juventud, Año 34, N. 11 (noviembre), 20-22; Roth, A. "¿Catastrofismo? iSí! Diálogo Universitario, 10(2), 11-15.

${ }^{8}$ Para profundizar las características del uniformismo y del actualismo, y contrastarlos con el catastrofismo o diluvialismo, V. Hammërly, D. (1946). Conflictos entre la fantasía y la ciencia. Montevideo: Impresora L.I.G.U; Morris, H. (1980). Geología: ¿actualismo o diluvialismo? Terrasa, Barcelona: Clíe.

${ }^{9}$ Oficial naval, hidrógrafo y meteorólogo. Diputado por Durham (1841-1843), gobernador de Nue- 
tín de la marina real británica, Beagle (Burkhardt, 1999, 39).

El padre de Charles montó en cólera cuando se enteró. El tío Josiah Wedgwood se encargó de convencerlo y, finalmente, Charles tuvo la venia paterna y los recursos para viajar (Burkhardt, 1999, 40, 41).

El 5 de setiembre tuvo la entrevista con el capitán Fitz-Roy. La posibilidad de Darwin casi se frustró porque al capitán no le gustó la nariz del joven naturalista. Fitz-Roy era partidario de la antropometría. El formato y las medidas nasales de Darwin "evidenciaban" -según la interpretación del capitán- pereza y vacilación. Finalmente, pese a esa "desventaja", Darwin fue aceptado. El joven de 22 años compartiría el camarote con el generoso, pero difícil capitán. Fueron muchos los enfrentamientos que tuvieron durante los cinco años de viaje, pero siempre Fitz-Roy cedió. El marino era un evangélico ferviente, creacionista a ultranza, que aceptaba las diferencias sociales, incluso la esclavitud de los negros, como parte del "sistema" establecido por Dios. Darwin disentía con esta posición, como así también con la inhumana disciplina naval. Tal situación lo llevó a retraerse y guardar sus opiniones. Esta y otras experiencias similares le hicieron ver cuán difícil era, para la sociedad victoriana, aceptar ideas diferentes a las establecidas.

El Beagle era un bergantín de la Marina Real de 30 metros de eslora por siete de manga; pesaba 235 toneladas y estaba equipado con diez cañones. La tripulación constaba de unas 60 personas. Partió del puerto de Plymouth el 27 de diciembre de $1831 .^{10}$

Para Darwin, este viaje alrededor del mundo fue lo más significativo en toda su vida. Trabajó diligentemente recolectando numerosos especímenes, estudiando algunos y disecando otros. En sus cuadernos anotaba minuciosamente lo que observaba. Además, acompañaba esas anotaciones con dibujos y gráficos. Los aspectos geológicos tuvieron prioridad sobre cualquier otro conocimiento. ¡Por supuesto que "leyó la realidad geológica" a través de las opiniones de Charles Lyell! ${ }^{11}$

A medida que iba avanzando el viaje, y después de permanecer en las Islas Galápagos, cada vez le costaba más aceptar la inmutabilidad de las especies. Ocurre que sus profesores en el seminario teológico, partidarios del

\footnotetext{
va Zelanda (1843-1845), jefe del Depto. de Meteorología, etc. Se suicidó en 1865 cuando tenía 59 años.

${ }^{10}$ Para conocer detalles de este viaje resulta interesante leer el registro del capitán FitzRoy. V. FitzRoy, R. (1839). Narrative of the surveying voyages of His Majesty.s chips Adventure and Beagle bettween the years 1826 and 1836. London. Hay una traducción al castellano, en varios tomos, hecha por el historiador y, por entonces capitán de fragata, Teodoro Caillet Bois publicado bajo el título: Narración de los viajes de levantamiento de los buques de S.M."Adventure" y "Beagle" en los años 1826 a 1836. Buenos Aires, 1933.

${ }^{11}$ Acerca de la influencia de Lyell sobre Darwin, V. Hammërly, D. (1946). Conflictos entre la fantasía y la ciencia. Montevideo: Impresora L.I.G.U., cap. X.
} 
"fijismo", le enseñaron que Dios había creado cada una de las variedades existentes dentro de un orden. Nada de esto dice la Biblia. Por eso, cuando, años más tarde, ordenó, examinó y sintetizó las observaciones biológicas que hizo durante el viaje, recordó tres datos que contrariaban la "inmutabilidad de las especies": 1. La sucesión de los tipos, 2. Los tipos representativos y 3. La evidencia de las Islas Oceánicas (Miller y Borin, 2004, 74-80). En cuanto a su relación con el fijismo, resulta esclarecedora una carta del 29 de setiembre de 1856 a J. D. Dana, en donde dice (Burkhardt, 1999, 185-186):

Se indignará bastante al oír que me estoy volviendo, de hecho yo diría que ya lo estoy, escéptico con respecto a la inmutabilidad permanente de las especies: sufro cuando hago esta confesión, pues gozaré de poca simpatía de aquellos cuya simpatía yo solo valoro. De cualquier modo, estoy seguro de que me reconocerá no haber llegado a una conclusión tan heterodoxa, sin mucha deliberación.

[...] Mi intención es proporcionar todos los hechos a favor de la inmutabilidad eterna de las especies y me he tomado muchas molestias para recopilarlos, como posiblemente podría hacer. Pero no sé en qué acabará mi trabajo; sí sé, sin embargo, que he estado trabajando duro y con honestidad en mi tema.

Del largo recorrido que realizó en los cinco años que duró el viaje, las mayores impresiones las recibió en las Islas Galápagos (en el Océano Pacífico, mil kilómetros al oeste de las costas del Ecuador) y en las islas del Cabo Verde, sobre el Atlántico, al oeste de Senegal (África).

\section{a. Después del viaje}

El Beagle atracó en el puerto de Falmouth el domingo 2 de octubre de 1836, por la tarde. Charles llegó a su casa en las últimas horas de la noche, después de casi cinco años de ausencia.

Ese viaje fue el acontecimiento más importante en su vida, pues regresó transformado en más de un sentido. No solamente le proporcionó materiales de estudio para el resto de su existencia, sino que cambió su estilo de vida. Ya no fue más aficionado a la caza, tampoco practicó deportes. Se convirtió en un hombre casero. También es cierto que en ese viaje contrajo una enfermedad, probablemente el "mal de chagas"12, que lo fue invalidando progresivamente. Se dedicó a catalogar los especímenes recolectados, super-

\footnotetext{
${ }^{12} \mathrm{~V}$. Anotación en su diario del 25 de marzo de 1825 (Viaje de un naturalista alrededor del mundo, Buenos Aires: Editorial El Ateneo, 1951, 386).
} 
visó la publicación de los informes científicos y comenzó a redactar el diario del viaje que se publicó en 1845 con el título Viaje de un naturalista alrededor del mundo ${ }^{13}$. De esta manera se convirtió en una celebridad científica. En 1838 ya era secretario de la Sociedad Geológica de Londres. Fue agasajado por la restringida clase intelectual y trabó amistad con el botánico Joseph Dalton Hooker (1817-1911) y con el médico y biólogo Thomas Henry Huxley (1825-1895) quienes se convirtieron en los más acérrimos defensores de las teorías de Darwin.

\section{b. Matrimonio, vida retirada y trabajo intelectual}

El 11 de noviembre de 1838 solicitó la mano de su prima Emma Wedgwood (1808-1896) y el 29 de enero del año siguiente contrajeron matrimonio. Establecieron su hogar en Londres. Un año después, la enfermedad que lo aquejaba fue progresando; este hecho lo condujo a evitar la vida social y retirarse a una casa de campo (1842) en el pueblo de Downs, Kent, a 16 millas de Londres, la cual pasó a ser su residencia definitiva. No obstante, trabajó muchísimo, gracias a la seguridad que le brindaba su excelente posición económica, los cuidados de su esposa y el afecto de sus diez hijos.

\section{c. Escritos}

Cuando Darwin regresó del viaje, poseía datos y registros de sus propias observaciones sobre la variación de las especies pero, como dice Daros ${ }^{14}$ $(2003,15,16)$ :

[...] No tenía aún una teoría de la evolución de las especies. Como siempre, las teorías son creaciones humanas de mentes preparadas para ello, y Darwin debió inventarla.

Una teoría es una interpretación de un cierto sector de la realidad. Ella no es necesariamente verdadera, pero da sentido a observaciones y experimentaciones. Una teoría implica, pues, algunos elementos estrictamente no observacionales (principios, conceptos teóricos de alta generalidad) y otros

\footnotetext{
${ }^{13} \mathrm{~V}$. Una de las tantas ediciones en castellano: Buenos Aires: Editorial El Ateneo, 1951(592 páginas). Otra fuente interesante para conocer los avatares de este viaje es el Diario que llevó Syms Covington, conocido como "el asistente de Darwin" quien le ayudó en la recolección de ejemplares diversos, los acondicionó cuidadosamente y se los despachaba a Inglaterra. Estuvo en el casamiento de Darwin y lo ayudó en la mudanza a su casa conyugal. Darwin durante veinte años mantuvo correspondencia con Covington quien se trasladó a Australia en 1839, en donde falleció en 1861 (Sosa, N. (2006). "Syms Covington, el sirviente de Darwin". Todo es Historia, Año XXXIX, № 470 [Buenos Aires, setiembre], 6-19).

${ }^{14}$ El Dr. William R. Daros es doctor en filosofía por la Universidad Nacional de Rosario, Argentina, investigador independiente del CONICET, profesor de las universidades UCEL y UAP y autor de decenas de libros, ensayos y artículos.
} 
sujetos a observación que constituyen los datos: pero un dato no adquiere sentido en sí mismo, sino dentro del marco de una teoría, la cual es inventada.

La teoría de la evolución darwiniana se apoya sobre un supuesto epistemológico y en cuatro principios [...]:

1. Variación: Los organismos vivientes varían sus rasgos de unos a otros en forma hereditaria, en un largo proceso continuo y gradual de reproducción.

2. Lucha por la existencia: En la naturaleza nacen muchos más organismos de los que sobreviven. Algunas variaciones confieren a unos una leve ventaja sobre otros en la inmensa competencia por la existencia.

3. Selección natural: Las variaciones seleccionadas por el medio, de acuerdo a su capacidad de adaptación, sin las que favorecen la reproducción y la supervivencia [...].

4. Especiación: La selección natural acumula variantes favorables produciendo subespecies o razas primero, y nuevas especies después, esto es, una forma de ser variada, relativamente estable y heredable en un largo período de tiempo.

Cuando Darwin comenzó a redactar el primer cuaderno hacia 1837, creía en el cambio geológico uniforme sostenido por Charles Lyell. De esta idea dedujo (Miller y Van Loon, 2004, 93):

"que la existencia continua de la vida sobre la tierra se explica si suponemos que las especies, que el cambio biológico tornó anticuadas, fueron reemplazadas por otras nuevas mejor adaptadas".

Darwin entendía que estas nuevas especies o se produjeron por una creación especial para compensar las pérdidas ocasionadas por la extinción, o evolucionaron a partir de sus antepasados anticuados. Hacia 1837 (Miller y Van Loon, 2004, 95) Darwin:

“estaba convencido de que la vida había 'evolucionado' y de que el surgimiento de nuevas especies era el resultado de la 'descendencia con modificación'”. 
Ahora, esa descendencia con modificación no explicaba cómo ni por qué se producía. Por eso Darwin se hizo dos preguntas: ¿Qué impulsa la evolución? ¿Qué la dirige? En un principio adhirió a las ideas de Lamarck diciendo que esas variaciones o "nuevas especies", se originaron por generación espontánea; es decir, de materia inerte surgieron seres vivos; pero pronto abandonó esta idea, pues entendió que organismos simples podían originar otros más complejos sin desaparecer. Para hallar respuesta a las dos preguntas planteadas, llegó a la conclusión de que la evolución se servía de dos leyes: la competencia (lucha por la existencia) y la selección natural. O sea que sobrevivía el más apto y que se seleccionaba a esos más aptos para que se perpetuaran ${ }^{15}$. La única alternativa para el funcionamiento de la selección deliberada era la competencia ciega, fuerza sin inteligencia, que elimina lo inadecuado (débil) y, por lo tanto, al sobrevivir el tiempo necesario, existen mejores posibilidades para transmitir a las próximas generaciones esas ventajas cualitativas que le permitieron sobrevivir.

Sin embargo, Darwin, si bien conocía el papel selectivo de la competencia, no la comprendió completamente hasta que se topó con el libro de Thomas Robert Malthus (1766-1834): Ensayo sobre el principio de la población (1798). Malthus, clérigo, economista y matemático, egresado de Cambridge, profesor de Economía Política e Historia Moderna en dicha universidad desde 1805 y hasta su muerte, llegó a la conclusión de que la población crece cuando hay más alimentos y se frena cuando hay hambrunas, enfermedades y guerras. O sea que estas "catástrofes" actuaban como "selección natural" para evitar la superpoblación, porque la población crece en progresión geométrica, mientras que los alimentos en progresión aritmética. Esta teoría se oponía al crecimiento indefinido del iluminismo, visión optimista del S. XVIII por la cual la fertilidad de una sociedad acarrearía el progreso económico. Malthus propiciaba que los políticos y los trabajadores sociales no debieran intentar paliar los efectos devastadores de esas calamidades porque eran los encargados de eliminar a los más débiles (en este caso los más indefensos, los pobres). La naturaleza no puede ser mejorada; por lo tanto, los intentos de los asistencialistas sociales por alterar esos designios provocarán incrementos demográficos insostenibles que aumentarán los sufrimientos que se pretenden evitar. Según Malthus, si la población no era controlada, continuaría duplicándose cada 25 años. En poco tiempo se agotarían los recursos naturales, los alimentos y la lucha por la supervivencia se tornaría feroz.

\footnotetext{
${ }^{15}$ Algunos autores sostienen que Darwin, en principio, no atribuyó la selección a la naturaleza, sino más bien la entendía como una elección consciente del Creador.
} 
Este razonamiento matemático era la herramienta que Darwin necesitaba para estar seguro de que la selección natural era la fuerza directiva de la evolución que estaba aguardando. Concluyó que en la lucha por la supervivencia los individuos dotados de variaciones favorables sobrevivirían, mientras que los menos afortunados perecerían.

En 1842 preparó un resumen, escrito a lápiz, con sus ideas, pero demasiado breve (35 páginas) y carente de respaldo científico como para publicarlo. Dos años después redactó un sólido ensayo de 250 páginas en el que estaba bien desarrollada su teoría, pero tampoco lo publicó. Siguió trabajando. Hacia 1844 la consideró terminada. Así se lo expresó a su esposa Emma en carta del 5 de julio de 1844 (Burkhardt, 1999, 108):

\section{Mi querida Emma:}

Acabo de terminar el esbozo de mi teoría de las especies. Sí, como creo, mi teoría es cierta y si es aceptada, incluso por un juez competente, constituirá un paso considerable para la ciencia.

Pero tampoco la dio a publicidad, ¿por qué? Se han presentado tres razones por las que postergó tantos años la publicación de su libro cumbre: 1ㅇ - No quería ni polemizar con los que pensaban distinto, ni ser perseguido por los religiosos victorianos. 2ㅇ-- Sus propias convicciones cristianas. 3 ㅇ La responsabilidad científica. Darwin sabía que si una teoría no era respaldada por suficientes hechos observables, quedaría en la categoría de hipótesis y, por lo tanto, rechazada por la comunidad científica. Él entendía que todavía le faltaba reunir mayor cantidad de datos, de tal forma que la deducción fuera inevitable.

En 1846 publicó un trabajo sobre geología de América del Sur y durante los próximos ocho años hizo un estudio comparado de los cirrípedos (una variedad de crustáceos), publicando dos libros; uno en 1851 y otro en 1854. En 1856 comenzó a preparar un libro que pensó titular La selección natural. El 18 de junio de 1858 fue un llamado de atención para la prudencia de Darwin. Ese día recibió un escrito del joven naturalista, Alfred Russell Wallace (1823-1913) $)^{16}$, titulado "Ensayo sobre la tendencia de las variaciones a separarse indefinidamente del tipo originario", en el que bosquejaba el desarrollo

\footnotetext{
${ }^{16}$ Wallace realizó investigaciones en el Amazonas (1848-1852) y en el archipiélago Malayo (18541862). Sin conocer los trabajos de Darwin, formuló una teoría de la selección natural similar en 1858. Acerca de los acuerdos y diferencias entre Darwin y Wallace, V. Oosterwal, G. (1974). "La pregunta que Darwin nunca contestó". Juventud, Año 39, № 2 (febrero), 23-26.

V. Darwin, Ch. (1957). "Datos históricos del desarrollo de las ideas sobre el origen de las especies antes de la primera edición de esta obra", en El origen de las especies por medio de la selección natural. México: Editorial Grijalbo, XV-XXIII.
} 
de las especies por medio de la selección natural; debía evaluarlo. Darwin se quedó sorprendido, pues los conceptos eran muy similares a los suyos. De inmediato le escribió a Ch. Lyell para comentarle lo sucedido. Ahora tenía otro problema: Si daba a conocer su teoría, podría acusársele de plagio. Finalmente decidió escribir un artículo, junto con Wallace que se publicó en el diario de la Sociedad Linneana el $1^{\circ}$ de julio de 1858 , titulado "Sobre la tendencia de las especies a crear variedades; y sobre la perpetuación de las variedades de las especies por medio de la selección natural". Esta circunstancia, el consejo de su hno. Erasmo y el de otros amigos, como así también que hacia 1859 la evolución era un hecho generalmente aceptado ${ }^{17}$, a pesar de que su mecanismo todavía no estaba claro, lo decidieron a terminar su libro que tituló Sobre el origen de las especies por medio de la selección natural o preservación de las razas favorecidas en la lucha por la vida, que fue publicado el 24 de noviembre de 1859. Esta primera edición de 1.250 ejemplares se agotó en un día. La segunda edición de 3.000 ejemplares salió a la venta el 7 de enero de 1860 . Para 1876 se habían vendido 60.000 copias ( 24.000 solamente en Inglaterra), y traducido a todos los idiomas europeos.

En 1868 publicó La variación de los animales y de las plantas bajo la acción de la domesticación.

\section{El origen del hombre}

El abordaje de este tema lo pospuso porque sabía que su posición al respecto sería motivo de controversia. Las primeras ideas acerca del origen del hombre como fruto de las variaciones de las especies, las fue gestando durante su famoso viaje, particularmente cuando observó a los pueblos canoeros que ocupaban la Tierra del Fuego y las islas adyacentes: Onas o Shelknam-Manekenk, Alakalufes y Yámanas $^{18}$; sin embargo, no las concretó "en blanco y negro" hasta mucho más adelante. Primero, en un ensayo titulado La expresión de las emociones en el hombre y los animales; $y$, finalmente, cuarenta años después, cuando había reunido suficientes "evidencias" para fundamentar su teoría, dio a publicidad, en febrero de 1871, Descendencia del hombre y la selección en relación al sexo, en dos tomos, cuyo propósito era incluir a la especie humana dentro del proceso de

\footnotetext{
${ }^{17}$ V. Darwin, CH. (1957). "Datos históricos del desarrollo de las ideas sobre el origen de las especies antes de la primera edición de esta obra", en El origen de las especies por medio de la selección natural. México: Editorial Grijalbo, XV-XXIII.

${ }^{18}$ Acerca de estos pueblos, V. Hammërly, D. (1952). "Los pueblos canoeros de Fuego Patagonia y los límites del hábitat Alakaluf" en RUNA, vol. V (Buenos Aires), 134-179.
} 
la evolución biológica. Allí expresó su convicción de que el hombre también era producto de transformación evolutiva de otros mamíferos, como las demás especies, porque se sintió apoyado en autores que, influidos por el darwinismo, le precedieron en la publicación de sus trabajos como: Carl Vogt: Lecciones sobre el hombre (1862); Thomas Huxley: Lugar del hombre en la naturaleza (1863); Charles Lyell: La antigüedad del hombre (1863); de Rolle: El hombre visto a través de la teoría darwinista (1865); Mac Lennan: Matrimonio primitivo (1865); John Lubbock (1834-1913): Los tiempos prehistóricos (1865) y el Origen de la civilización (1870); Buchner: El hombre según las ciencias (1870).

\section{Los “Tres Mosqueteros” de Charles Darwin}

Así como Alejandro Dumas padre (1802-1870), en su famosa novela histórica Los Tres Mosqueteros inmortalizó a los tres fieles espadachines como defensores del rey Luis XIII de Francia (1610-1643), Darwin tuvo tres espadas incondicionales que fueron "más papistas que el papa" al adoptar y difundir el evolucionismo. Se trata de Herbert Spencer, Thomas H. Huxley y Ernest H. Haeckel.

\section{Herbert Spencer (1820-1903)}

\section{Noticia biográfica y formación}

Nació en Derby, Reino Unido. No recibió educación formal, pues fue educado en su casa y, apasionado por el saber, fue autodidacta. Interesado por la mecánica, trabajó como ingeniero en los ferrocarriles (1837-1846). Posteriormente se dedicó a estudiar geología y biología. Entre 1848 y 1853 colaboró con el director del afamado periódico The Economist de Londres.

Antes de conocer la teoría de Darwin, tomó contacto con el evolucionismo lamarkiano y se adhirió a la hipótesis de la transmisión de los caracteres adquiridos. Así elaboró una interpretación de la realidad sobre bases evolucionistas.

Se lo considera el fundador de la filosofía evolucionista en Inglaterra. Sobresalió por sus investigaciones sobre el cambio social desde la perspectiva evolucionista. Elaboró un sistema filosófico, al que denominó filosofía sintética, sobre base evolucionista que abarcaba e integraba todas las áreas del conocimiento. Fue uno de los más destacados exponentes del optimismo victoriano. Dice el Dr. Fermín Chávez $(1981,26)$ : 
[...]Partidario de la evolución sin término, para quien el progreso era, no un accidente sino una necesidad. [...] Decía que la ciencia es el saber parcialmente unificado, mientras que la filosofía es el conocimiento completamente unificado.

\section{Estas ideas tienen un trasfondo claramente iluminista}

\section{Escritos}

La primera obra publicada fue Social Statics ${ }^{19}$ (La estática social) en 1851, en la que destaca la importancia de la libertad individual y de la ciencia. En 1855 publicó Principles of Psychology en la que afirma que las características individuales se desarrollan, gradualmente, por evolución. En 1862 apareció First Principles (Primeros principios) en donde presenta la ley de la evolución que ampliaría en su siguiente trabajo en dos tomos: Principles of Biology (Principios de biología, 1864-1867), explayándose sobre la ley de la adaptación al medio. Entre 1876 y 1896 dará a luz su obra más extensa (tres volúmenes) titulada Principles of Sociology. Otro trabajo importante es Essays, Scientific, Political and Speculative (Ensayos científicos, políticos y especulativos) en dos volúmenes (1858-1863) en donde presenta el impacto de la evolución sobre el pensamiento científico, político y filosófico. Tampoco se debe olvidar Principles of Ethics (1892 -1893) en dos volúmenes. Como se puede apreciar, Spencer fue un escritor prolífico y gran espada del evolucionismo; a él se debe la expresión "la supervivencia del más apto".

\section{Thomas Henry Huxley (1825-1895)}

\section{Noticia biográfica, formación y actividades}

Nació en Ealing, hoy un suburbio de Londres. Se graduó de médico en la Universidad de Londres en 1845 e inmediatamente ingresó a la Marina Real como cirujano auxiliar. Los viajes por los mares de Australasia le permitieron hacer observaciones sobre las especies que habitaban los mares tropicales. Ese primer período de servicio se extendió hasta 1850, cuando regresó a Londres fue incorporado a la Royal Society, aunque continuó colaborando con la Marina hasta 1853. En este lapso escribió varios trabajos científicos. Al año siguiente fue designado profesor de Historia Natural y Paleontología en la Escuela Real de Minas de Londres.

\footnotetext{
${ }^{19} \mathrm{El}$ título completo es: Social Statics, or the Conditions Essential to Human Happiness, Specified and the First of them Developed.
} 
Cuando apareció El origen de las especies (1859), Huxley se convirtió en el gran divulgador del darwinismo en el Reino Unido, mediante conferencias pronunciadas desde 1860 hasta su deceso, que contribuyeron a la aceptación de Darwin en los círculos científicos.

Se le atribuye haber ideado la palabra "agnosticismo" para indicar que el conocimiento ("gnosis") de lo infinito y de lo absoluto es inaccesible para la mente humana; por lo tanto, es imposible saber si existe o no Dios. Un agnóstico no es, necesariamente, ni ateo ni creyente.

\section{Escritos}

Produjo numerosos ensayos sobre biología y zoología. Uno de sus principales libros fue Evidencias de la situación del hombre en la naturaleza (1863).

\section{Ernst Heinrich Haeckel (1834-1919)}

Fue la espada más combativa a favor del darwinismo y su divulgador en el mundo de habla germana.

\section{Noticia biográfica, formación y actividades}

Nació en Potsdam (Prusia) y estudió Medicina y Biología en la universidades de Berlín y Würzburgo. Se doctoró en la primera universidad en 1857. Ejerció la Medicina hasta que fue designado (1862) profesor de Anatomía Comparada en la Universidad de Jena. A partir de 1865 y hasta 1908 agregó la cátedra de zoología en la misma universidad.

Con ayuda del evolucionismo, intentó construir una teoría que unificara la biología con la ciencia en general, incluyendo la religión. El Dr. Ferrater Mora sintetiza así su pensamiento $(1975$, t. I ,797):

Partiendo de sus investigaciones biológicas y de su complementación del darwinismo por la ley fundamental biogenética, según la cual la evolución del individuo corresponde a la evolución de la especie, Haeckel desarrolló una filosofía enteramente naturalista, que transformó poco a poco en un monismo panteísta.[...] Rechaza toda consideración metafísica y toda especulación sobre los problemas de Dios, la libertad y la inmortalidad, pero coloca como fondo de su filosofía una concepción dogmática, un materialismo determinista [...] No hay en la totalidad de cuanto existe más que la Naturaleza, pero esta se halla dotada de movimiento propio, no solo en los seres vivos, sino también en la materia inorgánica. El movimiento es la energía, y el universo y la historia no son más que el progreso de la gran evolución de 
una Naturaleza cuya finalidad última es el propio Dios que se convierte de este modo en conciencia de la Naturaleza.

Este monismo extremo fue divulgado por toda Alemania por la Liga Monista fundada en 1906, alcanzando gran aceptación, pero combatido por buena parte de los filósofos y por los círculos científicos antidogmáticos.

Como sabemos, mientras Darwin en su principal libro, de unas 400 páginas, dedicó diez a la embriología, cuatro y media a la morfología y solo alude a la teoría celular; pues el resto del libro está destinado a los problemas de adaptación y herencia, Haeckel magnificó la influencia del darwinismo en esas áreas casi no tocadas por el propio Darwin.

Más darwinista que Darwin, Haeckel fue conocido como el "patriarca", el "profeta" o el "pontífice" del darwinismo; porque, mientras el creador de la teoría sostenía que todas las especies derivaban de varias formas primitivas estructuradas por el Creador, Haeckel enseñó que todos los seres proceden de una forma primitiva muy rudimentaria y más sencilla que la ameba. El biólogo alemán consideró a El origen de las especies como el anti-Génesis porque Darwin, de un solo golpe, aniquiló el dogma de la creación. Indudablemente Haeckel, con su ultradarwinismo, fue más lejos que el propio Charles Darwin, atribuyendo a este conceptos que nunca siquiera esbozó.

\section{Escritos}

Haeckel también fue un escritor prolífico. Los trabajos publicados pueden clasificarse en obras de carácter científico y de divulgación.

\section{Obras científicas:}

Monographie der Radiolaren (Monografía acerca de los radiolarios), cuatro partes, 1862-1868. Entwicklungsgechichte der Siphonophoren, (Historia de la evolución de los sifonoforos), 1869; Monographie der Kalkschwämme (Monografía acerca de los espongiarios calcáreos), 1872; etc.

\section{Obras de divulgación:}

Generelle Morphologie der Organismen, allgemeine Grundzüge der organischen Formenwissenschaft, mechanisch begründet durch der von Ch. Darwin Reformierte Deszendenz theorie, dos tomos, 1866 (Morfología general de los organismos. Fundamentos generales de la ciencia orgánica de la forma, mecánicamente basada en la teoría reformada de la descendencia de Carlos Darwin); Natürliche Schöpfungsgechichte, 1868 (Historia natural 
de la creación, 1879, 1905); Ueber die Entstehung und den Stammbaum des Menschengeschlechts, 1868 (Sobre el origen y árbol genealógico de la especie humana); Ziele un Wege der heutigen Entwicklungsgeschichte, 1875 (Fines y caminos de la actual historia de la evolución); Der Monismus als Band Zwischen Religión und Wissenschaft. Glaubensbekenntnis eines Naturforschers, 1893 (El monismo como nexo de unión entre la religión y la ciencia. Confesión de fe de un naturalista, 1893). ${ }^{20}$

\section{Darwin, la religión y Dios}

Entre muchos grupos cristianos se ha hecho aparecer a Darwin como ateo y enemigo de la religión. Estamos en condiciones de afirmar que se trata de una acusación gratuita, por lo tanto, carente de fundamento.

Aunque su padre no era cristiano bautizó a su hijo Charles en la Iglesia Anglicana. Sus hermanas eran devotas y, durante su adolescencia, lo instaban a leer la Biblia. De hecho estudió teología y estuvo a punto de graduarse y ser clérigo. Sus grandes orientadores y luego amigos: los Profs. Adam Sedgwick y John Henslow, geólogo y botánico, respectivamente, eran miembros del clero anglicano. Cuando acompañó a Sedgwick en sus excursiones geológicas por Gales, concurrió dominicalmente a los cultos.

Probablemente durante el viaje con el Beagle y con certeza después, la fe de Darwin se fue deteriorando. ¿Causas? Varias. Entre ellas haber leído algunos libros de F. W. Newman (hno. del famoso Cardenal), misionero anglicano en Irak que se adhirió al unitarismo ${ }^{21}$, abandonando la Biblia y la creencia en la salvación por Cristo. Con motivo de la muerte de su hija Annie de tan solo diez años ${ }^{22}$, perdió su fe en un Dios de amor, al no conciliar ese atributo de Dios con el sufrimiento. En una carta de 1879, "Darwin se confesaba abiertamente como creyente en la existencia de Dios, pero como agnóstico en cuanto consideraba incapaz de probar esta existencia" (Daros, 2003, 21).

\section{Síntesis}

1. Si bien el evolucionismo era conocido antes que Darwin publicara sus primeros trabajos, en el Origen de las Especies planteó la teoría de que las

\footnotetext{
${ }^{20}$ Para completar la bibliografía, v. Ferrater Mora, J. (1975). Diccionario de Filosofía. Buenos Aires: Editorial Sudamericana, t. I, 798

${ }^{21}$ Grupo cristiano de origen italiano (S.XVI), antitrinitario (aceptaba solo al Padre como Dios), rechazó la necesidad del bautismo y la salvación por la fe. Favoreció la interpretación personal de la Biblia.

Condenó el sobrenaturalismo dentro del cristianismo, dando un giro hacia el racionalismo.

${ }^{22}$ Anne Elisabeth falleció en Malvern el 23 de abril de 1851. Estuvo cuidada por su padre, puesto que su madre estaba Dolwn (Kent) en avanzado estado de embarazo. Resultan conmovedoras las cartas que Charles dirigió, durante esos días de zozobra, a su esposa (V. Burkhardt, F. (Edit.). Cartas de Darwin (18251859), 144-146.
} 
especies evolucionan porque la Naturaleza selecciona las características útiles para que el individuo sobreviva y se reproduzca. La supervivencia del más fuerte es la "del mejor adaptado, del más sano, del que se ha salvado de la depredación, del más hábil para reproducirse en una nueva generación". ${ }^{23}$

2. En cuanto al hombre, en La descendencia del hombre y la selección sexual (dos tomos, 1871), propone que los seres humanos y los grandes monos tienen un antepasado común.

\section{Conclusiones}

A esta altura de la exposición, estamos en condiciones de arriesgar algunas conclusiones:

1. ¡Cuán importante es la influencia de los maestros sobre sus alumnos -para bien o para mal- no solo en la transmisión de conocimientos y de valores, sino también en el descubrimiento y motivación de sus vocaciones (caso de los profs. Sedgwick y Henslow)!

2. Debemos reflexionar acerca del daño que se puede causar al transmitir un concepto o teoría falsos, como por ejemplo: el “fijismo" o la condición "plana" de la Tierra o el geocentrismo y, más aún, atribuyéndoselo a Dios o como expresados en la Biblia, sin la correspondiente verificación.

3. La seriedad académica, la responsabilidad y la prudencia de Darwin se manifestaron al no apresurarse en dar a conocer las conclusiones. Pensó más en los perjuicios que podría ocasionar, que en los posibles beneficios. Siempre debiéramos preguntarnos: ¿Lo que voy a decir, es verdadero, está verificado? Si lo fuera, ¿es necesario que lo diga?, si lo digo, ¿voy a edificar o a destruir?

4. No se puede negar que el conocimiento y divulgación del evolucionismo darviniano causó un impacto no solo en los círculos académicos sino

${ }^{23}$ William Daros, Op.cit, 18. Esta idea, potenciada, servirá de fundamento para justificar el racismo. El gran biólogo-genetista japonés Motoo Kimura niega esta afirmación, sosteniendo que una especie sustituye a la otra no por mejor adaptada, sino porque tuvo suerte (azar). La selección natural no sería la fuerza que dirige toda la evolución, ya que no toda variación evolutiva es necesariamente adaptativa. Kimura lidera la teoría de la neutralidad. (V. Sorman, G. (1989). Los verdaderos pensadores del siglo XX. Buenos Aires: Atlántida, 82-92). 
sobre la sociedad toda, pues fue un eslabón más a favor del proceso de secularización de la vida; del paso de la dependencia del hombre de Dios a la independencia de Él; de la trascendencia a la inmanencia, del teocentrismo hacia el antropocentrismo. Un retorno a Protágoras de Abdera (¿485-410 a.C.?) en cuanto a que el "hombre es la medida de todas las cosas" o, peor aún, a la dependencia del azar y de la necesidad (Monod, 1985).

5. Hay que reconocerle a Darwin el aporte al estudio serio de la naturaleza, aunque no se compartan todas sus conclusiones.

6. Recordar que Darwin se centró en que las especies derivaban por variación de otras especies (adaptación y herencia), de varias formas primitivas y no de una sola. Incluso no descartó la intervención del Creador.

7. Su mente, condicionada por el "fijismo", sufrió un quiebre al encontrar, en sus observaciones, que la naturaleza no se comportaba así; había variaciones que explicó por medio de dos mecanismos: la lucha por la existencia y la selección natural.

8. Aunque Darwin se despegó del lamarkismo, al darwinismo también se le adjudicó la creencia en la transmisión de los caracteres adquiridos.

9. Darwin circunscribió sus conclusiones a las ciencias naturales, pero sus "espadas", y otros seguidores, las transpolaron a las sociales. Así Spencer sobredimensionó la importancia de la lucha por la existencia y formuló -como ya dijimos- el concepto de "supervivencia del más apto". Huxley rechazó la creencia en Dios y acompañó esa posición con la negación de que todos los hombres son iguales, dando así pie a la idea de que unos hombres son superiores a otros. El hiperdarwinismo de Haeckel, lo condujo al monismo y a exagerar la importancia de la lucha por la existencia.

10. La obsesión de la lucha por la existencia justificará el belicismo, el armamentismo y será responsable de la muerte de millones de seres humanos por genocidio o por guerras.

11. La cuestión del origen del hombre por evolución, alimentó la fantasía de los materialistas que atribuyeron al darwinismo la posibilidad del origen 
simiesco de la humanidad, dando origen a toda suerte de teorías arriesgadas y contradictorias. La peligrosidad de esos conceptos que señalaban equivocadamente diversas especies humanas como originarias de otras tantas ramas de los monos antropomorfos, dio lugar a prejuicios racistas enunciados en nombre de la ciencia. La hipótesis de que gradualmente se pasó de la bestia más evolucionada al infrahombre, de este al hombre para llegar al superhombre, alimentó la germanofilia "mesiánica" de Friedrich Nietzsche (1844-1900) que derivó en la atrocidad de los diversos totalitarismos.

12. Con frecuencia se ha acusado a Darwin de ateo. Nada más alejado de la verdad. Si bien es cierto que cuando zarpó a bordo del Beagle (1831) había abandonado el cristianismo práctico, siguió siendo creyente en Dios hasta su muerte. Fue sepultado en la Abadía de Westminster (Londres).

La experiencia de vida de Charles Robert Darwin, cuya obra produjo un cambio de $180^{\circ}$ en el pensamiento occidental, ha puesto de manifiesto la gravitación que tiene, para la estructuración de la cosmovisión personal, la influencia de las ideas transmitidas por maestros, amigos y libros. Además, nos hace tomar conciencia de la trascendencia del accionar de un docente y de un escritor sobre alumnos y lectores. 


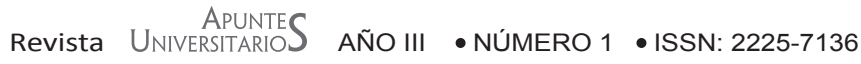

\section{Referencias}

Burkhardt, F. (Ed.). (1999). Cartas de Darwin (1825-1859). Madrid: Cambridge University Press.

Chávez, F. (1981). “Sarmiento spenceriano”. Todo es Historia, Año XV, N. ${ }^{\circ} 173$ (Buenos Aires, 26).

Darwin, Ch. (1996). Textos fundamentales. Barcelona: Ediciones Altaza.

Daros, W. (2003). “Charles Darwin: Agnóstico y creyente”. Invenio, Año 6, N. 10.

Downs, R. (1970). Libros que han cambiado el mundo. Buenos Aires: Aguilar.

Ferrater, J. (1975). Diccionario de Filosofía (Dos tomos). Buenos Aires: Editorial Sudamericana.

Hammërly, D. (1946). Conflictos entre la fantasía y la ciencia. Montevideo: Impresora Ligu.

Hammërly, D. (1948). El desafío de los yacimientos de carbón y petróleo. Montevideo: Impresora Ligu.

Miller, J., Van Loon, B. (2004). Darwin para principiantes. Buenos Aires: Era Naciente.

Monod, J. (1985). El azar y la necesidad. Barcelona: Tusquets editores. 